\title{
Altered mRNA Expression and Cell Membrane Potential in the Differentiated C17.2 Cell Model as Indicators of Acute Neurotoxicity
}

\author{
Jessica Lundqvist, ${ }^{1}$ Christina Svensson, ${ }^{1}$ Kristina Attoff,, and Anna Forsby ${ }^{1,2}$
}

\begin{abstract}
Using general cytotoxicity assays in combination with in vitro tests for organ-specific toxicity has been proposed as an alternative approach to animal tests for estimation of acute systemic toxicity. Here, we present the C17.2 neural progenitor cell line as an option for estimation of acute neurotoxicity. The C17.2 cells were differentiated for 6 days in serum-free N2 medium with brain-derived neurotrophic factor and nerve growth factor to a mixed culture of neurons and astrocytes. The cells were then exposed to noncytotoxic concentrations of acetylsalicylic acid, atropine, digoxin, ethanol, nicotine, or strychnine for 48 hours and the mRNA levels of glial fibrillary acidic protein, $\beta$ III-tubulin, and heat shock protein 32 were analyzed as biomarkers for astrocytes, neurons, and cellular stress respectively. As a functional endpoint, the cell membrane potential (CMP) was monitored after acute addition of each compound to the differentiated C17.2 cells, by using the fluorescent FLIPR ${ }^{\circledR}$ membrane potential assay. Nicotine [3.2E-04 M], atropine [1.2E-05 M], or strychnine [6.4E-05 M] resulted in altered gene expression of at least one biomarker for each compound, indicating alerts for neurotoxicity. The three compounds also induced depolarization of the CMP at the lowest observed effect concentrations $9.5 \mathrm{E}-05 \mathrm{M}$ of nicotine, $1.5 \mathrm{E}-05 \mathrm{M}$ of atropine, and 6.9E-07 M of strychnine. The non-neurotoxic compounds acetylsalicylic acid, ethanol, and digoxin did neither affect the mRNA levels, nor the CMP. This study showed that the differentiated C17.2 cells might be useful for estimation of acute neurotoxicity by analyzing expression of mRNA biomarkers and CMP alterations.
\end{abstract}

Keywords: acute neurotoxicity, astrocytes, C17.2 cells, cell membrane potential, HSP32, mRNA biomarkers, neuronal in vitro model, neurons

\section{Introduction}

$\mathbf{E}$ STIMATION OF HUMAN ACUTE TOXICITY, that is, symptoms shown after a single dose and within 24 hours after exposure, has traditionally relied on data from animal testing, human intoxication cases, and epidemiology studies. Implementation of the Registration, Evaluation, Authorization, and Restriction of Chemicals (REACH) program in Europe $^{1}$ (EC No 1907/2006), together with the High Productive Volume (HPV) program ${ }^{2,3}$ founded by Environmental Protection Agency (EPA) in the United States, would result in a massive increase of laboratory animals being used for toxicity hazard identification of chemicals.

Extensive efforts have been made to develop tests for the estimation of acute systemic toxicity. The tests could be general cytotoxicity assays, which were evaluated for the prediction of human acute oral toxicity and for LD50 in mice and rats in the validation projects the Multicenter Evaluation of In vitro Cytotoxicity ${ }^{4-6}$ (MEIC), the Registry of Cytotoxicity ${ }^{7}$ (RC), and Validation study of In Vitro Cytotoxicity Tests Methods ${ }^{8,9}$ performed in collaboration between the National Toxicology Program Interagency Center for the Evaluation of Alternative Methods (NICEATM), and the European Center for Validation of Alternative Methods (ECVAM). The studies showed that $60 \%-70 \%$ of the chemicals tested displayed good correlation between the in vitro derived general cytotoxicity data (IC50) and the estimated human lethal blood concentration or rodent LD50 values. However, the toxicity of $30 \%-40 \%$ of the chemicals tested were either overestimated or underestimated by the in vitro assays and hence, the chemicals were defined as outliers. ${ }^{5}$ Overestimated toxicity in vitro may be due to toxicokinetic features, which are related to absorption, distribution, metabolism, and excretion (ADME), whereas underestimated toxicity using general

\footnotetext{
${ }^{1}$ Department of Neurochemistry, Stockholm University, Stockholm, Sweden.

${ }^{2}$ Swetox, Karolinska Institutet, Unit of Toxicology Sciences, Södertälje, Sweden.

(c) Jessica Lundqvist et al., 2017; Published by Mary Ann Liebert, Inc. This article is available under the Creative Commons License CC-BY-NC (http://creativecommons.org/licenses/by-nc/4.0). This license permits non-commercial use, distribution and reproduction in any medium, provided the original work is properly cited. Permission only needs to be obtained for commercial use and can be done via RightsLink.
} 
cytotoxicity as the only endpoint may neglect organ-specific toxicity caused by the chemicals or the lack of biotransformation.

The overall aim of the EU-funded Framework 6 project "Optimisation and Pre-validation of an In Vitro Test Strategy for Predicting Human Acute Toxicity" (ACuteTox) was to develop and validate a robust test strategy for the prediction of human acute oral systemic toxicity using alternative in vitro models. ${ }^{10,11}$ Some of the chemicals selected in the ACuteTox study were also included and identified as outliers in the MEIC and NICEATM/ECVAM validation studies. The results from the ACuteTox project showed that the most promising model for detecting acute adverse effects in the nervous system, denoted acute neurotoxicity, was the aggregating rat brain cell culture (AGGR). The AGGR was kept in vitro for $\sim 3$ weeks to develop a mixed population of neurons, astrocytes, and oligodendrocytes. ${ }^{12}$ Together with the general cytotoxicity that was analyzed in the murine fibroblast cell line BALB/3T3 by the Neutral Red Uptake (NRU) viability assay, ${ }^{8,13,14}$ the AGGR model was recommended as a gold standard to be used as a tool for alerting chemicals that may induce acute neurotoxicity. ${ }^{12,15}$

It is desirable to use simple and robust cell models (e.g., cell lines) instead of using primary cell cultures for ethical and economic reasons, but also to make it possible to perform high-throughput screening (HTS) of a large number of chemicals. The objective of this study was to elucidate the capacity of the murine neural progenitor cell line $\mathrm{C} 17.2$ to alert for chemicals that may induce acute toxicity by a neuronal mode of action. The effects of atropine, acetylsalicylic acid, digoxin, ethanol, nicotine, and strychnine (all reference chemicals used in the ACuteTox project) on mRNA biomarker expression and cell membrane potential (CMP) were studied. The biomarker assay was identified in the ACuteTox project as a useful indicator of brain-specific toxicity by using the AGGR model ${ }^{12}$ and the CMP analysis was shown to be a promising functional general key event in the human neuroblastoma SH-SY5Y cell line. ${ }^{16}$ Here, we show that analyses of the CMP and mRNA biomarker expression in the differentiated $\mathrm{C} 17.2$ neural cell model may provide alternative test approach to alert for chemicals that may cause acute neurotoxicity.

\section{Materials and Methods}

\section{C17.2 cell line and culture condition}

The C17.2 cell line is derived from multipotent neural stem cells that were isolated from neonatal mouse cerebellum and immortalized by avian myelocytomatosis viralrelated oncogene $(v-m y c)$ transfection. ${ }^{17}$ The cells were a generous gift from Professor Sandra Ceccatelli (Karolinska Institute, Stockholm, Sweden), with permission from Professor Evan Snyder (Harvard Medical School, Boston, MA). The cells were grown in $55 \mathrm{~cm}^{2}$ cell culture dishes (No. 430167; Corning, Inc.) in DMEM (No. 41966-029) supplemented with $5 \%$ donor horse serum (No. 26050-088), 10\% fetal calf serum (No. 16140-071), $2 \mathrm{mM}$ L-glutamine (No. 25030-024), $100 \mathrm{U}$ penicillin/mL, and $100 \mu \mathrm{g}$ streptomycin/ $\mathrm{mL}$ (No. 15240-062; all from Gibco, Life Technologies), denoted as complete DMEM. The cells were detached every 3rd to 4th day using a solution of $0.05 \%$ trypsin and $0.02 \%$ EDTA (No. 25300-054) and reseeded in cell culture dishes at a density of $1.5 \times 10^{5}$ cells/dish in $10 \mathrm{~mL}$ complete
DMEM. All cell cultures were kept in a humidified atmosphere of $5 \% \mathrm{CO}_{2}$ at $37^{\circ} \mathrm{C}$.

\section{Differentiation of C17.2 cells}

The $\mathrm{C} 17.2$ cells were differentiated into a mixed culture of astrocytes and neurons as previously described. ${ }^{18}$ Briefly, for mRNA expression analysis $3.5 \times 10^{4}$ cells were seeded per well in a six-well plate (No. 3516; Corning, Inc.) in $2 \mathrm{~mL}$ complete DMEM and for CMP experiments cells were seeded in 96-well plates (No. 3599; Corning, Inc.) at a density of $1.2 \times 10^{3}$ cells per well in $100 \mu \mathrm{L}$ of complete DMEM 1 day before medium change to differentiation medium. The C17.2 cells were differentiated using DMEM:F12 medium (No. 31330-038) with $1 \mathrm{mM}$ L-glutamine (No. 25030-024), $100 \mathrm{U}$ penicillin/mL and $100 \mu \mathrm{g}$ streptomycin/mL (No. 15240-062), and with modified N2 supplements (to a final concentration of $100 \mu \mathrm{g} / \mathrm{mL}$ apo-transferrin from bovine; No. 02152334 MP Biomedicals), $5 \mu \mathrm{g} / \mathrm{mL}$ insulin from bovine (I-1882), $20 \mathrm{nM}$ progesterone (P-8783), $100 \mu \mathrm{M}$ putrescine dihydrochloride (P-5780), and $30 \mathrm{nM}$ sodium selenite (S-5261; all from Sigma Aldrich) together with recombinant human brain-derived neurotrophic factor (BDNF, No. 248$\mathrm{BD})$ and recombinant mouse $\beta$-nerve growth factor (NGF, No. 256-NG; $10 \mathrm{ng} / \mathrm{mL}$ of each neurotrophic factor; R\&D Systems) denoted as differentiation medium. The cells were differentiated for 6 days before treatment with each test compound. The differentiation medium was exchanged on day 3 in the 6well plates and no exchange of the medium was performed but factors were added in the wells of the 96-well plates.

\section{Test chemicals}

The six compounds, acetylsalicylic acid (CAS 50-78-2), atropine sulfate monohydrate (CAS 5908-99-6), digoxin (CAS 20830-75-5), nicotine (CAS 54-11-5) and strychnine (CAS 57-24-9; all from Sigma Aldrich), and ethanol (CAS 64-17-5; VWR) were chosen from the reference chemicals list used in the ACuteTox project. ${ }^{19}$

In the CMP assay, the cells were differentiated for 6 days before the experiments and the compounds were tested in eight concentrations or more and the highest concentration tested was $1 \mathrm{mM}$ for nicotine, atropine, and acetylsalicylic acid. The highest concentration tested was $6.0 \mathrm{E}-01 \mathrm{M}$ for ethanol (equal to $27.6 \%$ ), $1.0 \mathrm{E}-04 \mathrm{M}$ for strychnine, and $1.0 \mathrm{E}-04 \mathrm{M}$ for digoxin (limit of solubility). The concentrations used to assess for alerts using the mRNA biomarker strategy were based on cytotoxic concentrations, previously determined by the 3T3/NRU cytotoxicity assay. ${ }^{19}$ The differentiated C17.2 cells were exposed for 48 hours to one hundred $(1 / 100)$, one tenth $(1 / 10)$, and one fifth $(1 / 5)$ of the concentration causing $50 \%$ reduced NRU, as compared to unexposed control cells (IC50) in the 3T3/NRU assay. Hence, the concentrations used for assessment of acute neurotoxicity in this study were $4.3 \mathrm{E}-05 \mathrm{M}, 4.3 \mathrm{E}-04 \mathrm{M}$, and 8.6E-4 M for acetylsalicylic acid; $1.2 \mathrm{E}-06 \mathrm{M}, 1.2 \mathrm{E}-05 \mathrm{M}$, and $2.5 \mathrm{E}-05 \mathrm{M}$ for atropine; $6.6 \mathrm{E}-06 \mathrm{M}, 6.6 \mathrm{E}-05 \mathrm{M}$, and $1.3 \mathrm{E}-04 \mathrm{M}$ for digoxin; $1.5 \mathrm{E}-03 \mathrm{M}, 1.5 \mathrm{E}-02 \mathrm{M}$, and $2.9 \mathrm{E}-$ $02 \mathrm{M}$ for ethanol; 3.2E-05 M, 3.2E-04 M, and $6.4 \mathrm{E}-04 \mathrm{M}$ for nicotine; and 6.4E-06 M, 6.4E-05 M, and 1.3E-04 M for strychnine. Acetylsalicylic acid, atropine, ethanol, nicotine, and strychnine were dissolved in $\mathrm{KRH}$ buffer $(125 \mathrm{mM}$ 
$\mathrm{NaCl}, 5.0 \mathrm{mM} \mathrm{KCl}, 1.2 \mathrm{mM} \mathrm{MgSO}, 1.2 \mathrm{mM} \mathrm{KH}_{2} \mathrm{PO}_{4}$, $2.0 \mathrm{mM} \mathrm{CaCl}_{2}, 6.0 \mathrm{mM}$ D-glucose, and $25 \mathrm{mM} \mathrm{HEPES}$ [free acid], $\mathrm{pH}$ adjusted to 7.4 by $1.0 \mathrm{M} \mathrm{NaOH}$ ) for the CMP assay or in differentiation medium for mRNA biomarker analysis, whereas digoxin was dissolved in dimethyl sulfoxide (DMSO). A noncytotoxic concentration of DMSO $(0.5 \%$ [ vol/ $/ \mathrm{vol}])$ was used for all concentrations of digoxin and for its counterpart control.

\section{Cell membrane potential}

To evaluate acute changes in CMP in differentiated C17.2 cells after addition of the test compounds, a fluorescentbased assay using FLIPR ${ }^{\circledR}$ Membrane Potential Assay Kit (FMP Red, No. 8123; Molecular Devices) was used. The FMP Red probe was reconstituted in $10 \mathrm{~mL} \mathrm{KRH} \mathrm{buffer,}$ which was aliquoted and stored at $-20^{\circ} \mathrm{C}$. The FMP probe partitions across intra- and extracellular membranes in a voltage-dependent manner. Depolarization of the cell membrane initiates the movement of FMP into the cell with subsequent binding to hydrophobic sites, which results in an increased fluorescent signal. Conversely, membrane hyperpolarization triggers extrusion of FMP, from the cell and consequently, decreasing the fluorescent signal. ${ }^{20}$

Before the experiment, the medium was aspirated and the cells were rinsed once with $200 \mu \mathrm{L} \mathrm{KRH}$ buffer and the FMP-aliquot was further diluted 25 times and $90 \mu \mathrm{L}$ of the diluted FMP-solution was added per well, and the plate was incubated at $37^{\circ} \mathrm{C}$ for 20 minutes. The plate was then assayed at $37^{\circ} \mathrm{C}$ in a semi-HTS fluorescence reader (FlexStation II; Molecular Devices). The fluorescence 565/530 nm (em/ex) was registered every 2 seconds using bottom read settings. After initially 20 seconds baseline recording of the fluorescence intensity, $10 \mu \mathrm{L}$ of reference compound dilution (prepared at 10 times of the final concentration to the cells, in 8 concentrations) were transferred automatically by the internal pipetting function of the FlexStation II ("Flex mode") to the cell plate wells (five wells per concentration) and the fluorescence intensity was monitored for another 220 seconds. The mean values from the baseline recording was set to zero and the acute change in the CMP after addition of the compounds was quantified as the area under the curve using the SoftMax ${ }^{\circledR}$ Pro 4.8 software (Molecular Devices). Positive values corresponded to depolarization of the cell membrane, and negative values were considered to be a consequence of hyperpolarization. The CMP change was expressed as percent of the CMP change induced by $30 \mathrm{mM} \mathrm{KCl}$. To check for intrinsic fluorescence or quenching of FMP fluorescence by reference chemicals, $10 \mu \mathrm{L}$ of the four highest concentrations of the reference chemical dilution series were added to four wells containing only the FMP solution without cells.

\section{RNA purification, reverse transcription, and quantitative real-time $R T-P C R$}

Cell samples for analysis of mRNA expression were lysed and total RNA extraction was performed according to the manufacturer's protocol of GeneJET ${ }^{\mathrm{TM}}$ RNA Purification Kit (Fermentas, Thermo Scientific). DNase1 (Fermentas, Thermo Scientific) digestion was performed to remove possible contamination with DNA. To assess RNA integrity, $18 \mathrm{~S}$ and $28 \mathrm{~S}$ rRNA were analyzed on a $1 \%$ agarose gel and visualized using ethidium bromide under UV light. RNA concentrations were determined spectrophotometrically, followed by reverse transcription of total RNA using RevertAid $^{\mathrm{TM}}$ Minus First Strand cDNA Synthesis Kit (Fermentas, Thermo Scientific). The cDNA synthesis was performed according to the manufacturer's protocol.

Synthesized cDNA was used as template for quantitative real-time PCR using Maxima ${ }^{\mathrm{TM}}$ SYBR Green/Fluorescein qPCR Master Mix $(2 \times$; Fermentas, Thermo Scientific) according to the manufacturer's recommendations. Gene expression levels of the neuron biomarker $\beta$ III-tubulin, ${ }^{21}$ astrocyte biomarker glial fibrillary acidic protein ${ }^{22}$ (GFAP), and oxidative cell stress/cell survival biomarker heat shock protein $32^{23}$ (HSP32, also called heme oxygenase-1) were measured using the MyiQ ${ }^{\mathrm{TM}} 2$ Two-color Real-Time PCR Detection System (Bio-Rad laboratories) and normalized against the reference gene $\beta$-actin. Primer sequences used are listed in Table 1.

\section{Morphology study}

Phase contrast microscopy (Olympus; Condensor NA 0.3, Objective SPlan10PL NA 0.3 Olympus) was used to evaluate whether any morphological alterations were induced in differentiated C17.2 cell cultures that were exposed for 48 hours to the neurotoxic compounds nicotine [3.2E$04 \mathrm{M}$ ], atropine [1.2E-05 M], and strychnine [6.4E-05 M], as compared to nontreated control cells. Images were captured at $150 \times$ magnification by using a CCD camera (Olympus DP50). To visualize neurons by immunofluorescence, $2.8 \times 10^{3}$ cells were seeded and differentiated on sterile glass coverslips (No 1.5, $13 \mathrm{~mm}$; VWR) placed in a 24well plate (No. 3526; Corning, Inc.). After 7 days of differentiation, the medium was removed and the cells were fixed in $4 \%$ paraformaldehyde for 10 minutes at room

Table 1. Primer Sequences Used In the QRT-PCR Analysis

\begin{tabular}{|c|c|c|c|}
\hline Gene name (official symbol) & Primer sequence (mouse) & Gene ID & Concentration (nM) \\
\hline \multirow[t]{2}{*}{$\beta$-actin $(A c t b)$} & Forward: CTTCCTTCTTGGGTATGGA & \multirow[t]{2}{*}{ NM_007393 } & \multirow[t]{2}{*}{300} \\
\hline & Reverse: ACGGATGTCAACGTCACACT & & \\
\hline \multirow[t]{2}{*}{$\beta$ III-tubulin $(T u b b 3)$} & Forward: AGGCCCGACAACTTTATCT & \multirow[t]{2}{*}{ NM_023279 } & \multirow[t]{2}{*}{200} \\
\hline & Reverse: CTCTTTCCGCACGACATCTA & & \\
\hline \multirow{2}{*}{$\begin{array}{l}\text { Glial fibrillary acidic protein } \\
\text { (Gfap) }\end{array}$} & Forward: ATCGCCACCTACAGGAAAT & \multirow[t]{2}{*}{ NM_010277 } & \multirow[t]{2}{*}{300} \\
\hline & Reverse: GGATCTGGAGGTTGGAGAAA & & \\
\hline \multirow{2}{*}{$\begin{array}{l}\text { Heat shock protein } 32 \\
\quad(\text { Hmox } 1)\end{array}$} & Forward: CTGGTGATGGCTTCCTTGTA & \multirow[t]{2}{*}{ NM_010442 } & \multirow[t]{2}{*}{200} \\
\hline & Reverse: GGGAAGTAGAGTGGGGCATA & & \\
\hline
\end{tabular}


temperature, permeabilized in $100 \%$ methanol (VWR) 2 minutes, and blocked with PBS/2\% BSA for 20 minutes. In between every step several washing steps were performed with PBS. The cells were incubated with rabbit anti- $\beta$ IIItubulin (ab18207; Abcam, diluted 1:1000 in PBS/2\% BSA) for 1 hour in room temperature. The cells were washed in $\mathrm{PBS} / 2 \% \mathrm{BSA}$ before incubation for 30 minutes in room temperature with the secondary antibody goat anti-rabbit conjugated with AlexaFluor595 (A11012; Invitrogen, diluted $1: 400$ in PBS/2\% BSA). Nuclei were stained with $0.5 \mu \mathrm{g} /$ $\mathrm{mL}$ Hoechst in PBS for 10 minutes. The coverslips were mounted on microscope slides (VWR) using Fluoromount-G ${ }^{\circledR}$ (No. 0100-01; Southern Biotechnology Associates, Inc.) and sealed with nail polish the day after. The immunofluorescence was visualized with a fluorescence microscope Leica DM/IRBE 2. Images were taken with Hamamatsu Orca ER CCD camera and analyzed by Micro-Manager and ImageJ software program.

\section{Data analyses}

For compounds inducing alteration of the CMP, the concentration-dependent responses were fitted by global nonlinear regression with sigmoid curve fit and shared Hill's slope between every individual experiment for each compound. Results were analyzed using one-way ANOVA followed by Fischer's least significant difference test, $* * p<0.01, * * * p<0.001, * * * * p<0.0001$, as compared to control.

To analyze the relative changes in mRNA gene expression, $2^{-\Delta \Delta \mathrm{C}_{\mathrm{T}}}$ method was used. ${ }^{24}$ The threshold cycle $\left(\mathrm{C}_{\mathrm{T}}\right)$ values were obtained from the target genes and the reference gene and in turn used in the calculation of $\Delta \mathrm{C}_{\mathrm{T}}$ value for the treated cells $\left[\Delta \mathrm{C}_{\mathrm{T}}=\mathrm{C}_{\mathrm{T} \text { (target gene) }}-\mathrm{C}_{\mathrm{T} \text { (reference gene) }}\right]$ followed by subtraction of the $\Delta \mathrm{C}_{\mathrm{T}}$ value for the calibrator (untreated control), generating the $\Delta \Delta \mathrm{C}_{\mathrm{T}}$. The relative change (fold change) of the mRNA gene expression was calculated using the equation $2^{-\Delta \Delta \mathrm{C}_{\mathrm{T}}}$. The results from $\Delta \Delta \mathrm{C}_{\mathrm{T}}$ calculations were analyzed by one-way ANOVA, followed by Dunnett's test to determine statistically significant effects of the compounds on gene expression where ${ }^{\#} p<0.1$ and $* p<0.05$ as compared to unexposed control.

All data analyses were performed by using GraphPad Prism ${ }^{\circledR}$ Software 6.07.

\section{Results}

\section{Cell membrane potential}

Nicotine, atropine, and strychnine induced a concentrationdependent, immediate depolarization of the CMP in the differentiated C17.2 cells, whereas ethanol induced depolarization at the highest concentration tested, $600 \mathrm{mM}$ (equivalent to $27.6 \% \mathrm{w} / \mathrm{v}$ ). Neither acetylsalicylic acid, nor digoxin affected the CMP at the concentrations tested (Fig. 1). In comparison to $\mathrm{KCl}$-induced increase in fluorescence intensity (Emax) the maximum effect was about $35 \%$ for $1 \mathrm{E}-03 \mathrm{M}$ nicotine, $220 \%$ for $1 \mathrm{E}-03 \mathrm{M}$ atropine, and about $70 \%$ for $1 \mathrm{E}-$ $04 \mathrm{M}$ strychnine. The estimated lowest observed effective concentration (LOEC) of nicotine, atropine, or strychnine corresponding to $5 \%$ increase in relation to $\mathrm{KCl}$-induced effect on the fluorescence intensity was $9.5 \mathrm{E}-05 \pm 2.2 \mathrm{E}-05 \mathrm{M}$
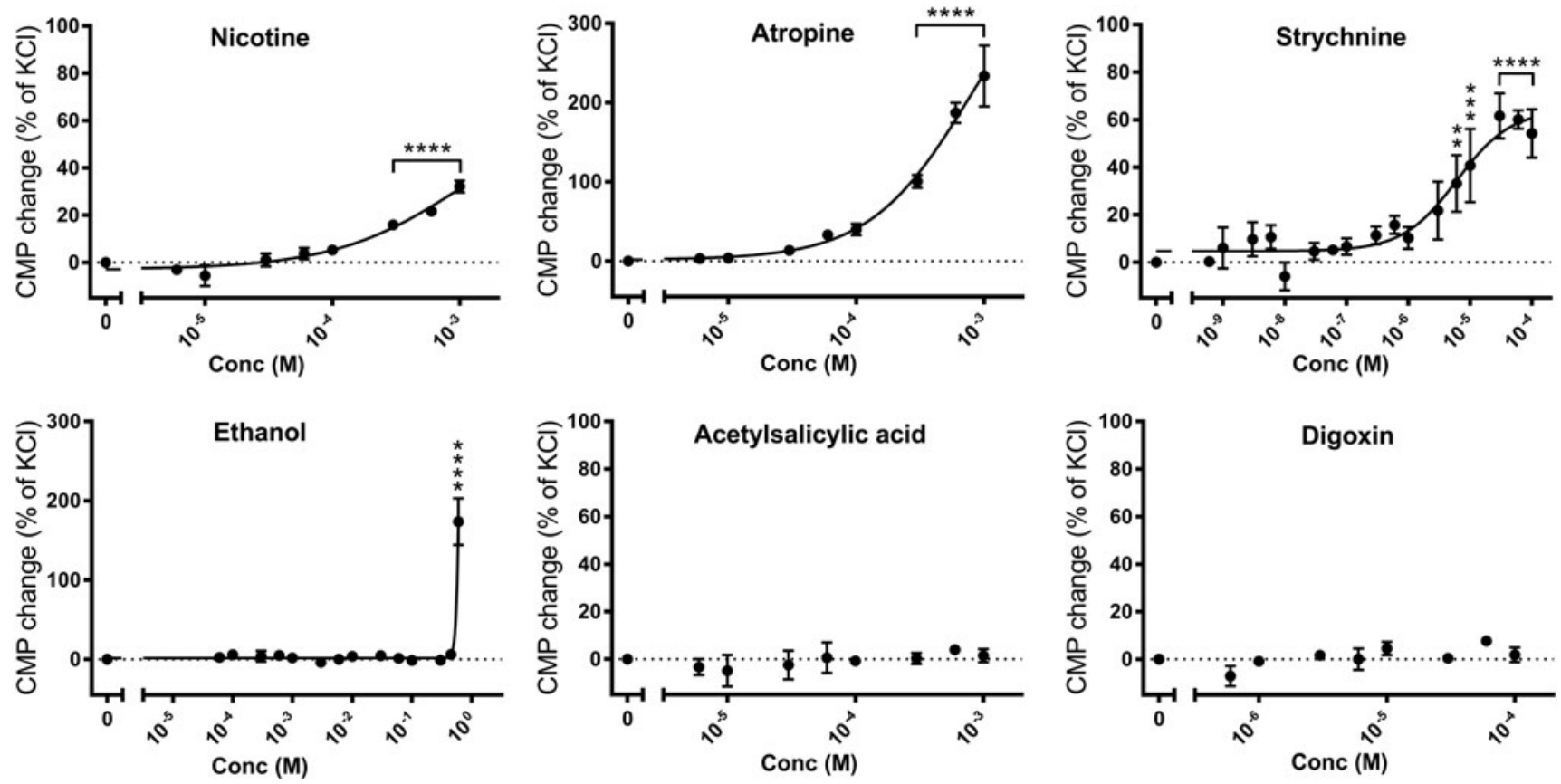

FIG. 1. Effects of nicotine, atropine, strychnine, acetylsalicylic acid, ethanol, and digoxin on the CMP in differentiated C17.2. The murine neural progenitor cell line, C17.2, was differentiated in serum-free N2 medium, supplemented with BDNF and NGF, for 6 days and loaded with the CMP-sensitive probe FMP. Acute addition of nicotine, atropine, and strychnine induced depolarization of the cell membrane whereas acetylsalicylic acid, ethanol, and digoxin did not induce any response. Data are presented as mean \pm SEM of three or four independent experiments and statistical analyses were performed by one-way ANOVA, followed by Fischer's least significant difference test. $* * p<0.01 ; * * * p<0.001 ; * * * *<<0.0001$. BDNF, brain-derived neurotrophic factor; CMP, cell membrane potential; NGF, nerve growth factor. 
for nicotine, $1.5 \mathrm{E}-05 \pm 1.4 \mathrm{E}-05 \mathrm{M}$ for atropine, and $6.9 \mathrm{E}-$ $07 \pm 2.6 \mathrm{E}-07 \mathrm{M}$ for strychnine. The LOECs are summarized in Table 2, together with LOECs for the compounds that were previously determined by using the differentiated human neuroblastoma SH-SY5Y cell model. ${ }^{16}$

\section{Levels mRNA biomarkers of neuron, astrocyte, and cell stress biomarkers}

Nicotine, atropine, and strychnine induced concentrationdependent effects on the gene expression of affected biomarkers after exposure to $1 / 100$ and $1 / 10$ of IC50 and also 1/5 of IC50 for nicotine (Fig. 2). The mRNA expression of the astrocyte biomarker GFAP was significantly upregulated in the differentiated $\mathrm{C} 17.2$ cells after treatment with $1 / 5$ and $1 / 10$ of IC 50 determined in the 3 T3/NRU assay ${ }^{19}$ for nicotine [6.4E-04 M and 3.2E-04 M, respectively] and downregulated by $6.4 \mathrm{E}-05 \mathrm{M}$ strychnine (1/10 of IC50) as compared to control cells. Strychnine [6.4E-05 M] and atropine [1.2E-05 M] induced a significant decrease of the $\beta$ III-tubulin mRNA levels. The mRNA level of the stress marker HSP32 was significantly decreased after exposure to atropine [1.2E-05 M]. Exposure to acetylsalicylic acid, digoxin, or ethanol did neither affect expression of the cell specific biomarkers, nor the HSP32 mRNA level as compared to control cells at any of the concentrations tested (Fig. 2). The concentrations of the compounds that altered the biomarker expression in the C17.2 cells are compiled in Table 2.

\section{Morphology}

The morphology of differentiated C17.2 cells was examined under a phase contrast microscope after the 48 hours of exposure to nicotine [3.2E-04 M], atropine [1.2E-05 M], and strychnine [6.4E-05 M]. No signs of cytotoxicity or degeneration were observed, and two cell phenotypes were clearly identified in the control cultures and in the cell cultures that were treated with the neurotoxic test compounds (Fig. 3).

\section{Discussion}

We evaluated the ability of the differentiated neural progenitor $\mathrm{C} 17.2$ cell line to improve the in vitro prediction of acute systemic human toxicity by using the CMP and mRNA biomarker expression as indicators of acute neurotoxicity as a complement to the general cytotoxicity (IC50) determined in the 3T3/NRU assay. We assumed that the mixed C17.2 culture of neurons and astrocytes would better mimic cells in the nervous system and hence, would identify compounds that are known to be neurotoxic. The endpoints were analyzed as promising key events upstream lethality, but downstream molecular initiating events in the nervous system. Altered CMP at noncytotoxic concentrations would indicate any disturbed neuronal function after acute exposure to chemicals and thus, alert for acute toxicity that is related to a neuronal mode of action by depolarization or hyperpolarization. A change in the ion homeostasis (especially in the intracellular $\mathrm{Ca}^{2+}$ concentration) may result in cellular stress and altered gene expression. Hence, the mRNA levels of the neuronal marker $\beta$ III-tubulin, astrocyte marker GFAP, and cell stress marker HSP32 were analyzed as a secondary

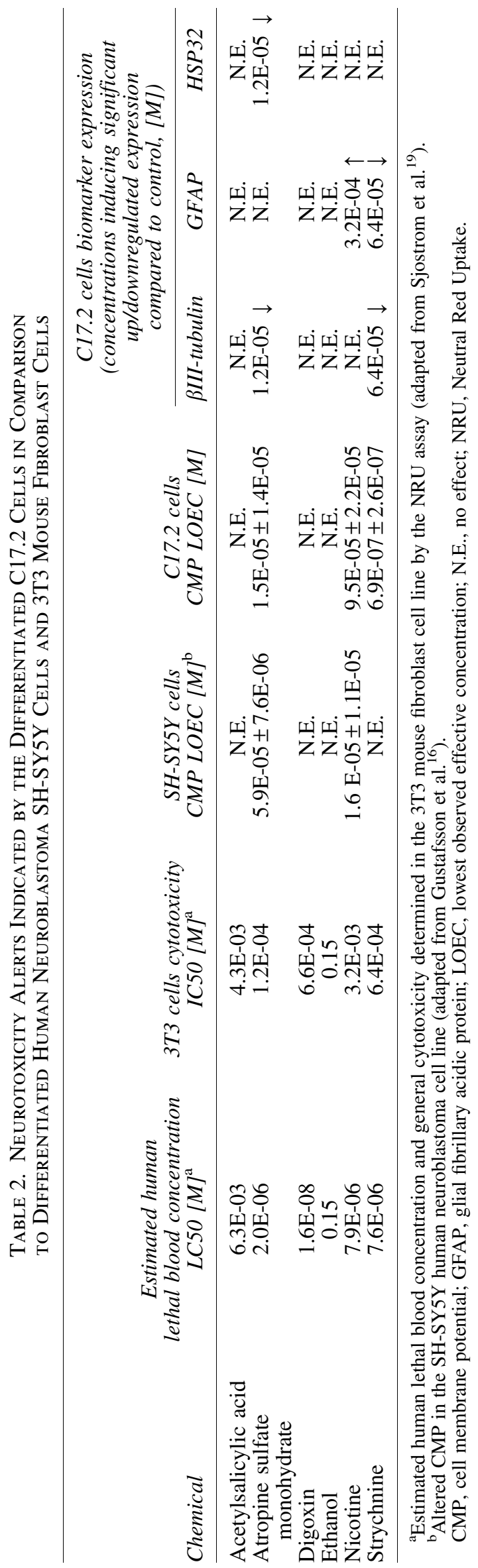



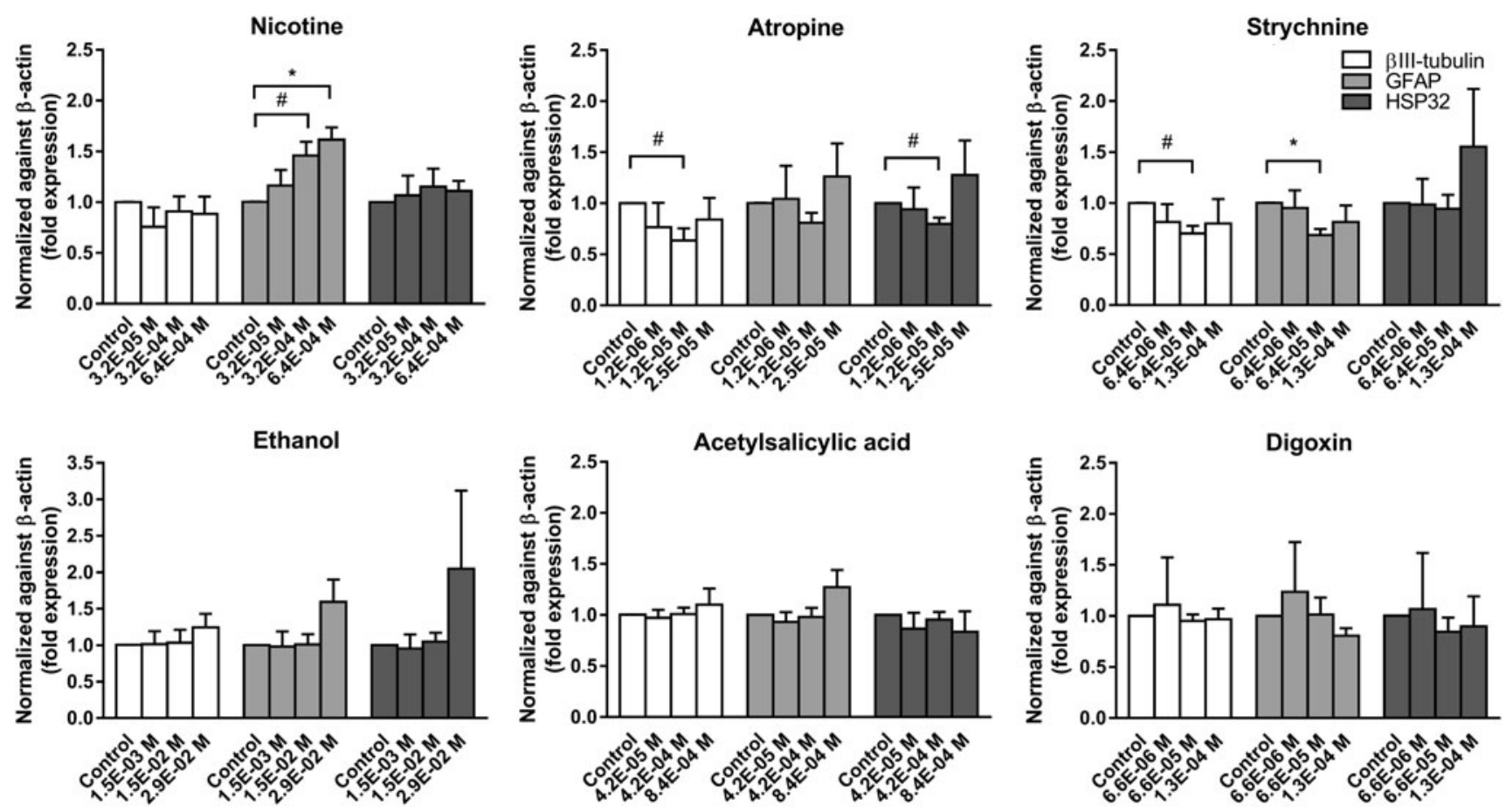

FIG. 2. Quantitative RT-PCR analysis of mRNA biomarkers in C17.2 cells. The $\beta$ III-tubulin (white), GFAP (gray), and HSP32 (dark gray) mRNA levels were determined in differentiated C17.2 cells after exposure for 48 hours to nicotine, atropine, strychnine, ethanol, acetylsalicylic acid, or digoxin at 1/100, 1/10, and 1/5 of the IC50, determined in the 3T3NRU cytotoxicity assay. ${ }^{19}$ The mRNA levels of the biomarkers were normalized against the reference gene $\beta$-actin and the results were analyzed by one-way ANOVA, followed by Dunnett's test. ${ }^{*} p<0.1, * p<0.05$ compared to each treatment's control (non-treated cells). Data are presented as mean \pm SEM of three or four independent experiments $(n=3-4)$. GFAP, glial fibrillary acidic protein.

endpoint. Six natural compounds with well-known modes of action were used as reference compounds, that is, acetylsalicylic acid, atropine, digoxin, ethanol, nicotine, and strychnine. As expected, atropine, nicotine, and strychnine were alerted as neurotoxic compounds in both the CMP and mRNA biomarker assays, whereas acetylsalicylic acid, digoxin, and ethanol did not affect any of the endpoints in the $\mathrm{C} 17.2$ cell model at noncytotoxic concentrations.

Nicotine is a nicotinic acetylcholine receptor ${ }^{25}$ (nAChR) agonist. Upon binding to the nAChR, a conformational change will occur and the channel, which is permeable to $\mathrm{Na}^{+}$and to a minor extent $\mathrm{Ca}^{2+}$, will open. The net influx of cations will cause depolarization of the cell membrane, which was also observed in the C17.2 cell model as an increase in the FMP fluorescence intensity. Atropine is a muscarinic acetylcholine receptor ${ }^{26}(\mathrm{mAChR})$ antagonist. The $\mathrm{mAChR}$ is a group of $\mathrm{G}$ protein-coupled receptors with five subtypes. The majority of the mAChR subtypes possesses depolarizing activity in the nervous system when treated with agonists. However, we observed an increase in the CMP of the differentiated C17.2 cells after exposure to atropine, indicating depolarization after blocking mAChR. One explanation to this observation could be that inhibitory AChR (M2 and M4) may be constitutively active to a low extent and that a blockage of these would result in an immediate depolarization. ${ }^{26}$ The mode of action of strychnine is primarily by binding to the glycine receptor in a competitive manner. ${ }^{27}$ The glycine receptor is permeable to $\mathrm{Cl}^{-}$and antagonists to the receptor attenuate hyperpolarization of the
CMP. Strychnine induced a depolarization of the CMP in our study. Again, the toxicity of an antagonist might be shown by attenuating a constitutive activity of the receptor, as suggested for atropine. Another possible explanation could be that attenuated activity of inhibitory ion channels may cause depolarization of the CMP as a result of the activity or leakage of inward current cation channels.

Acetylsalicylic acid, digoxin, and ethanol were not alerted for acute neurotoxicity in our test model. However, ethanol is a well-known sedative compound and it acts by at least three modes of action in neurons: (1) as a $\mathrm{GABA}_{\mathrm{A}}$ receptor agonist, resulting in enhanced $\mathrm{Cl}^{-}$influx, ${ }^{28}$ (2) as a glutamate NMDA receptor antagonist, preventing postsynaptic excitatory potential, ${ }^{29}$ and (3) by altering cell membrane fluidity. ${ }^{30}$ The overall effect of ethanol is attenuated excitability of brain neurons and sedation of the central nervous system as the lethal adverse outcome. ${ }^{31}$ However, we were not able to detect any effect on the CMP for concentrations up to $450 \mathrm{mM}$ of ethanol exposure in the differentiated C17.2 cell model, which is about five times higher than the lethal blood concentration. ${ }^{32}$ The reason may be that the neurons in the $\mathrm{C} 17.2$ cell population probably neither express $\mathrm{GABA}_{\mathrm{A}}$ receptors, nor NMDA receptors. The fact that only the highest concentration used in this study, that is, $600 \mathrm{mM}$ (corresponding to $27.6 \%$, w/v), generated an effect on the CMP shows that our cell model was not able to alert for ethanol-induced acute neurotoxicity. Digoxin is not reported to be neurotoxic and the main mode of action of digoxin is cardiotonic. Digoxin increases the intracellular free 
FIG. 3. Morphology of differentiated C17.2 cells after exposure with nicotine, atropine, and strychnine. The cells were cultured in serumfree N2-medium supplemented with BDNF and NGF for 6 days and thereafter exposed for 48 hours to differentiation medium (A) without addition of compounds (control) or with addition of (B) nicotine [3.2E-04 M], (C) atropine [1.2E-05 M], (D) strychnine [6.4E-05 M], and (E) immunofluorescence picture of control cells, arrow with feather indicates a neuron and a plain arrow indicate an astrocyte. In (F) the distribution of neurons and astrocytes in the cultures is shown. The concentrations are $1 / 10$ of IC50 determined in the 3T3 fibroblast, Neutral Red Uptake assay. All scale bars represent $50 \mu \mathrm{m}$.
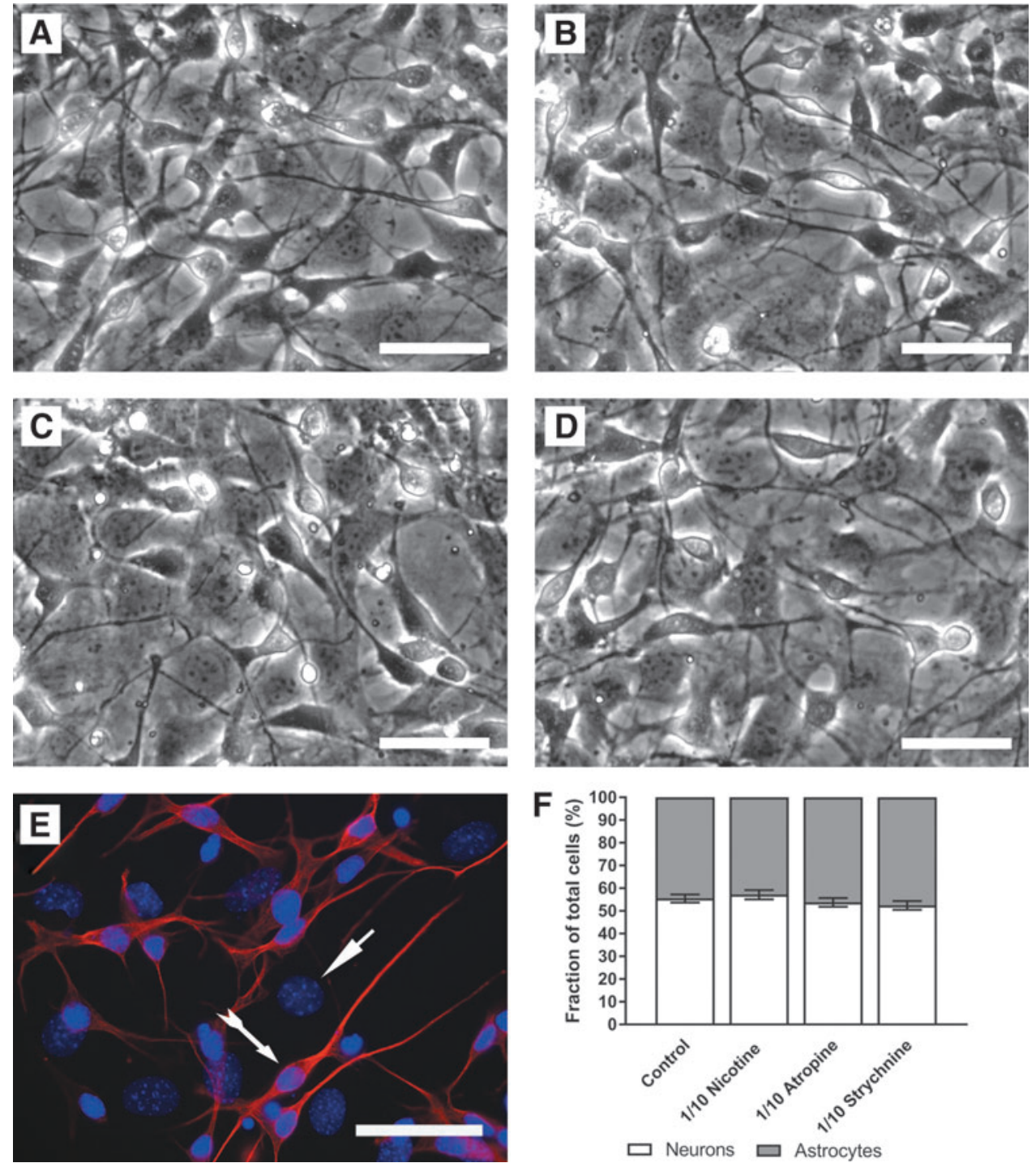

$\mathrm{Ca}^{2+}$ concentration in cardiac myocytes as a result of $\mathrm{Na}^{+} /$ $\mathrm{K}^{+}$-ATPase inhibition. One may expect that digoxin would affect the CMP in our cell model because of the possibility that the ion distribution over the cell membrane may be affected. However, the affinity of cardiac glycosides to $\mathrm{Na}^{+} /$ $\mathrm{K}^{+}$-ATPase may differ between the subunit isoforms of the enzyme. ${ }^{33}$ Furthermore, opposite effects of low concentrations of digoxin on hippocampal $\mathrm{Na}^{+} / \mathrm{K}^{+}$-ATPase activity have been observed. ${ }^{34}$ It appears that neither the human neuroblastoma SH-SY5Y, nor the C17.2 cell model express digoxin-sensitive neuronal $\mathrm{Na}^{+} / \mathrm{K}^{+}$-ATPase because no effects could be observed on the biomarker expression or the CMP in the C17.2 cells or any of the endpoints analyzed in the SH-SY5Y cell model. ${ }^{16}$ Taken together, digoxin induced lethality after acute exposure is probably not associated to acute neurotoxicity, but rather cardiac failure. The absence of effect of the nonsteroid anti-inflammatory drug acetylsalicylic acid on the CMP and biomarker expression was expected. When comparing the effects on CMP in C17.2 cell with the effects that were observed in the SH-SY5Y cell model, we could see that atropine and nicotine were identified as neurotoxic compounds at the same concentrations in both models but only the $\mathrm{C} 17.2$ cell model alerted strychnine as neurotoxic. ${ }^{16}$ This result then favors the C17.2 cell model over the SH-SY5Y cell model as an indicator of alerts for compounds that induce lethality by a neuronal mode of action.

One of the objectives of this study was to elucidate the possibility to replace primary aggregating rat brain cell cultures $^{12}$ with the mixed cell culture of differentiated C17.2 cells by studying the effects of the six compounds on mRNA biomarker expression. Our results showed that atropine, nicotine, and strychnine affected the expression of one or more of the biomarkers in the C17.2 cells in a concentration-dependent manner at non-cytotoxic concentrations. In the primary AGGR brain culture, digoxin increased the GFAP expression and ethanol decreased the NF-H expression after exposure at non-cytotoxic concentration. ${ }^{12}$ However, atropine, nicotine, and strychnine affected the mRNA biomarker levels only at concentrations that were within $\pm 0.5 \log 10$ units from the IC50 value determined by the 3T3/NRU assay. Acetylsalicylic acid did not induce any effect. ${ }^{12}$ This indicates that cells in the AGGR cultures may express digoxin-sensitive $\mathrm{Na}^{+} / \mathrm{K}^{+}$-ATPase isoforms, but lack functional $\mathrm{nAChR}, \mathrm{mAChR}$, and glycine receptors. From the six compounds we tested we conclude that the 
C17.2 cell model performed at least as well as the AGGR cultures. A more extensive study with a wider set of reference chemicals will be required to confirm this conclusion.

We quantified the number of neurons and astrocytes in the cultures that were exposed to concentrations of nicotine, atropine and strychnine that corresponded to $1 / 10$ of the IC50 determined in 3T3 mouse fibroblast cell line. Despite the fact that the CMP and the gene expression of neuronal and/or astrocyte mRNA biomarkers were affected, no effects were visible on the morphology of the cell cultures. This illustrates that histology or cell pathology, as acute toxicity endpoints, may not identify alterations in cell function such as neuronal signaling, energy metabolism, neurotransmitter uptake, or ion homeostasis, that is, features that may lead to lethal toxicity in vivo after acute exposure. ${ }^{35}$

Several studies such as the MEIC project, the RC, or the ACuteTox project indicated that in vitro toxicity data determined in cell cultures cannot stand alone as a safety assessment of human exposure. ${ }^{5,7,15}$ It is necessary to make extrapolations from in vitro toxicity concentrations to in vivo doses to be able to predict hazardous doses. Hence, information about the ADME of the chemical are essential parameters to include in the full estimation of the toxicity potential. The integrated test strategy, including in vitro test systems with relevant molecular targets and key events for toxicodynamic assessment, and computational models for estimation of the toxicokinetics and metabolism, should be the most promising way forward for non-animal-based hazard evaluation of chemical exposure. ${ }^{36-38}$ Nevertheless, a rough evaluation of the relevance of our results can be performed by comparing the concentrations that affected biomarker expression and altered CMP to the estimated human toxic blood concentrations. ${ }^{19}$ The estimated human blood concentration of atropine that induced $50 \%$ lethality (LC50) was reported to be about $2 \mu \mathrm{M}$ and we could see effects at 15 and $12 \mu \mathrm{M}$ in the CMP and biomarker assays respectively. For nicotine, the estimated LC50 was reported to be about $8 \mu \mathrm{M}$ and we could determine the LOEC to be $95 \mu \mathrm{M}$ in the CMP assay and $320 \mu \mathrm{M}$ affected the GFAP expression. For strychnine, the corresponding comparison was $8 \mu \mathrm{M}$ for the human LC50, $0.7 \mu \mathrm{M}$ for the CMP LOEC, and $64 \mu \mathrm{M}$ biomarkers. Hence, the concentrations found to affect one or two of the endpoints were approximately within the range of one order of magnitude from the LC50 (Table 2).

\section{Conclusion}

In conclusion, the results found in this study show that the differentiated C17.2 test system comprising analyses of alterations of the CMP and mRNA biomarker expression after exposure to chemicals appears to be useful for identification of compounds that induce acute toxicity by neuronal modes of action. The simplicity, robustness, and relatively low cost of the test system, together with the lack of ethical issues, make it attractive as a tool for high-throughput toxicity screening.

\section{Acknowledgments}

This study was financed by support from The Swedish Research Council (grant 521-2010-2804) and The Swedish Fund for Research Without Animal Experiments.

\section{Author Disclosure Statement}

No competing financial interests exist.

\section{References}

1. EC (2006). Regulation (EC) No. 1907/2006 of the European Parliament and of the Council of 18 December 2006 concerning the Registration, Evaluation, Authorisation and Restriction of Chemicals (REACH), establishing a European Chemicals Agency, amending Directive 1999/45/EC and repealing Council Regulation (EEC) No. 793/93 and Commission Regulation (EC) No. 1488/94 as well as Council Directive 76/769/EEC and Commission Directives 91/ 155/EEC, 93/67/EEC, 93/105/EC and 2000/21/EC. Off. J. Eur. Union, L396/1 of 30.12.2006. Commission of the European Communities. 2006:1-849.

2. U.S. EPA (U.S. Environmental Protection Agency). 1998. EPA to Expand Chemical Right-To-Know Program and Provide Public with Better Health Data. www.epa.gov/ history/topics/earthday/09.html (last accessed June 4, 2012).

3. U.S. EPA (U.S. Environmental Protection Agency). 2011. Basic information. www.epa.gov/hpv/pubs/general/basicinfo .htm (last accessed June 22, 2012).

4. Ekwall B, Clemedson C, Crafoord B, et al. MEIC evaluation of acute systemic toxicity: Part V. Rodent and human toxicity data for the 50 reference chemicals. Altern Lab Anim 1998:26 Suppl 2;571-616.

5. Ekwall B, Barile FA, Castano A, et al. MEIC evaluation of acute systemic toxicity: Part VI. The prediction of human toxicity by rodent LD50 values and results from 61 in vitro methods. Altern Lab Anim 1998:26 Suppl 2;617-658.

6. Ekwall B. Overview of the final MEIC results: II. The in vitro-in vivo evaluation, including the selection of a practical battery of cell tests for prediction of acute lethal blood concentrations in humans. Toxicol In Vitro 1999:13; 665-673.

7. Halle W. The Registry of Cytotoxicity: Toxicity testing in cell cultures to predict acute toxicity (LD50) and to reduce testing in animals. Altern Lab Anim 2003:31;89-198.

8. NIH Publication No. 07-4518. 2006. https://ntp.niehs.nih .gov/iccvam/docs/protocols/ivcyto-balbc.pdf (last accessed Feb. 15, 2017).

9. NIH Publication No. 07-4519. 2006. https://ntp.niehs.nih .gov/iccvam/docs/acutetox_docs/brd_tmer/at-tmer-complete .pdf (last accessed Feb. 15, 2017).

10. www.acutetox.eu/ (last accessed Feb. 15, 2017).

11. Clemedson C, Kolman A, Forsby A. The integrated acute systemic toxicity project (ACuteTox) for the optimisation and validation of alternative in vitro tests. Altern Lab Anim 2007:35;33-38.

12. Zurich M, Stanzel S, Kopp-Schneider A, et al. Evaluation of aggregating brain cell cultures for the detection of acute organ-specific toxicity. Toxicol In Vitro 2013:27;1416-1424.

13. Borenfreund E, Puerner JA. Short-term quantitative in vitro cytotoxicity assay involving an S-9 activating system. Cancer Lett 1987:34;243-248.

14. Clothier R, Dierickx P, Lakhanisky T, et al. A database of IC50 values and principal component analysis of results from six basal cytotoxicity assays, for use in the modelling of the in vivo and in vitro data of the EU ACuteTox project. Altern Lab Anim 2008:36;503-519.

15. Kinsner-Ovaskainen A, Prieto P, Stanzel S, et al. Selection of test methods to be included in a testing strategy to predict acute oral toxicity: An approach based on statistical analysis 
of data collected in phase 1 of the ACuteTox project. Toxicol In Vitro 2013:27;1377-1394.

16. Gustafsson H, Runesson J, Lundqvist J, et al. Neurofunctional endpoints assessed in human neuroblastoma SH-SY5Y cells for estimation of acute systemic toxicity. Toxicol Appl Pharmacol 2010:245;191-202.

17. Snyder EY, Deitcher DL, Walsh C, et al. Multipotent neural cell lines can engraft and participate in development of mouse cerebellum. Cell 1992:68;33-51.

18. Lundqvist J, El Andaloussi-Lilja J, Svensson C, et al. Optimisation of culture conditions for differentiation of C17.2 neural stem cells to be used for in vitro toxicity tests. Toxicol In Vitro 2013:27;1565-1569.

19. Sjostrom M, Kolman A, Clemedson C, et al. Estimation of human blood LC50 values for use in modeling of in vitroin vivo data of the ACuteTox project. Toxicol In Vitro 2008: $22 ; 1405-1411$.

20. www.moleculardevices.com (last accessed Feb. 15, 2017).

21. Roskams AJ, Cai X, Ronnett GV. Expression of neuronspecific beta-III tubulin during olfactory neurogenesis in the embryonic and adult rat. Neuroscience 1998:83;191-200.

22. Eng LF. Glial fibrillary acidic protein (GFAP): The major protein of glial intermediate filaments in differentiated astrocytes. J Neuroimmunol 1985:8;203-214.

23. Sharp FR, Zhan X, Liu DZ. Heat shock proteins in the brain: Role of Hsp70, hsp 27, and HO-1 (Hsp32) and their therapeutic potential. Transl Stroke Res 2013:4;685-692.

24. Livak KJ, Schmittgen TD. Analysis of relative gene expression data using real-time quantitative PCR and the 2(-delta delta C(T)) method. Methods 2001:25;402-408.

25. Albuquerque EX, Pereira EF, Alkondon M, et al. Mammalian nicotinic acetylcholine receptors: from structure to function. Physiol Rev 2009:89;73-120.

26. Brown DA. Muscarinic acetylcholine receptors (mAChRs) in the nervous system: some functions and mechanisms. J Mol Neurosci 2010:41;340-346.

27. Young AB, Snyder SH. Strychnine binding associated with glycine receptors of the central nervous system. Proc Natl Acad Sci U S A 1973:70;2832-2836.

28. Nestoros JN. Ethanol specifically potentiates GABAmediated neurotransmission in feline cerebral cortex. Science 1980:209;708-710.
29. Lovinger DM, White G, Weight FF. Ethanol inhibits NMDA-activated ion current in hippocampal neurons. Science 1989:243;1721-1724.

30. Goldstein DB, Chin JH, Lyon RC. Ethanol disordering of spin-labeled mouse brain membranes: correlation with genetically determined ethanol sensitivity of mice. Proc Natl Acad Sci U S A 1982:79;4231-4233.

31. Davies $M$. The role of GABAA receptors in mediating the effects of alcohol in the central nervous system. J Psychiatry Neurosci 2003:28;263-274.

32. Paton A. Alcohol in the body. BMJ 2005:330;85-87.

33. Katz A, Lifshitz Y, Bab-Dinitz E, et al. Selectivity of digitalis glycosides for isoforms of human Na,K-ATPase. J Biol Chem 2010:285;19582-19592.

34. Oselkin M, Tian D, Bergold PJ. Low-dose cardiotonic steroids increase sodium-potassium ATPase activity that protects hippocampal slice cultures from experimental ischemia. Neurosci Lett 2010:473;67-71.

35. Forsby A, Bal-Price AK, Camins A, et al. Neuronal in vitro models for the estimation of acute systemic toxicity. Toxicol In Vitro 2009:23;1564-1569.

36. Yoon M, Campbell JL, Andersen ME, et al. Quantitative in vitro to in vivo extrapolation of cell-based toxicity assay results. Crit Rev Toxicol 2012:42;633-652.

37. Blaauboer BJ. Biokinetic modeling and in vitro-in vivo extrapolations. J Toxicol Environ Health B Crit Rev 2010:13; 242-252.

38. Sung JH, Esch MB, Shuler ML. Integration of in silico and in vitro platforms for pharmacokinetic-pharmacodynamic modeling. Expert Opin Drug Metab Toxicol 2010:6;10631081.
Address correspondence to: Dr. Anna Forsby Department of Neurochemistry Stockholm University

Svante Arrhenius väg 16 Stockholm SE-106 91

Sweden

E-mail: anna.forsby@neurochem.su.se 